\title{
Bilateral Asymptomatic Fibrous-Ankylosis of the Temporomandibular Joint Associated with Rheumatoid Arthritis: A Case Report
}

\author{
Carolina Ortigosa CUNHA ${ }^{1}$ \\ Lívia Maria Sales PINTO ${ }^{1}$ \\ Luana Menezes de MENDONÇA ${ }^{1}$ \\ Aline Dantas Diógenes SALDANHA ${ }^{1}$ \\ Ana Cláudia de Castro Ferreira $\mathrm{CONTI}^{2}$ \\ Paulo César Rodrigues CONTI ${ }^{1}$ \\ ${ }^{1}$ Department of Prosthodontics, Bauru Dental School, USP - University of São Paulo, Bauru, SP, Brazil \\ ${ }^{2}$ Department of Orthodontics, UNOPAR - University of North Paraná, Londrina, PR, Brazil
}

\begin{abstract}
The American Academy of Orofacial Pain (AAOP) defines ankylosis of the temporomandibular joint (TMJ) as a restriction of movements due to intracapsular fibrous adhesions, fibrous changes in capsular ligaments (fibrous-ankylosis) and osseous mass formation resulting in the fusion of the articular components (osseous-ankylosis). The clinical features of the fibrous-ankylosis are severely limited mouth-opening capacity (limited range of motion during the opening), usually no pain and no joint sounds, marked deflection to the affected side and marked limitation of movement to the contralateral side. A variety of factors may cause TMJ ankylosis, such as trauma, local and systemic inflammatory conditions, neoplasms and TMJ infection. Rheumatoid arthritis (RA) is one of the systemic inflammatory conditions that affect the TMJ and can cause ankylosis. The aim of this study is to present a case of a female patient diagnosed with bilateral asymptomatic fibrous-ankylosis of the TMJ associated with asymptomatic rheumatoid arthritis. This case illustrates the importance of a comprehensive clinical examination and correct diagnosis of an unusual condition causing severe mouth opening limitation.
\end{abstract}

Key Words: ankylosis, temporomandibular joint, mouth opening limitation, rheumatoid arthritis.

\section{INTRODUCTION}

The American Academy of Orofacial Pain (AAOP) defines ankylosis of the temporomandibular joint (TMJ) as a restriction of movements due to intracapsular fibrous adhesions, fibrous changes in capsular ligaments (fibrous ankylosis) and osseous mass formation resulting in the fusion of the articular components (osseous ankylosis). TMJ ankylosis impairs functions such as speech, chewing and mouth opening. Limited jaw opening and decreased translation movement characterizes ankylosis in adults, and it is classified according to the location (intra-articular versus extra-articular), type of involved tissue (bony, fibrous or mixed) and fusion extent (complete versus incomplete) $(1,2)$.
The clinical features of the fibrous-ankylosis are severely limited mouth-opening capacity (limited range of motion during the opening), usually no pain and no joint sounds, marked deflection to the affected side and marked limitation of movement to the contralateral side. The imaging features of the fibrous-ankylosis are a visible joint space (differently from the osseous ankylosis) and no clear definition of any joint structures. The condylar translation is very restricted or inexistent (2). All signals and symptoms must be present for a fibrous-ankylosis diagnostic (3).

A variety of factors may cause TMJ ankylosis, such as trauma, local and systemic inflammatory conditions, neoplasms and TMJ infection. The most common etiological factors are trauma and infection. Roychoudhury et al. (4) studied 50 patients and found

Correspondence: Carolina Ortigosa Cunha, Departamento de Prótese, Faculdade de Odontologia de Bauru, USP, Alameda Dr. Octávio Pinheiro Brisolla, 9-75, Vila Universitária, 17012-901 Bauru, SP, Brasil. Tel: +55-14-9631-1456. e-mail: carol.ortigosa@gmail.com 
that trauma was the cause of ankylosis in $86 \%$ of these cases. Although the etiology of TMJ ankylosis is categorized broadly into infections and injuries, the propensity to the development of TMJ ankylosis is not known (5). According to Chandra and Dave (6), systemic diseases, such as ankylosing spondylitis, rheumatoid arthritis (RA) and psoriasis, account for a small percentage of TMJ ankylosis (10\% of the cases).

RA is a systemic disorder which may involve many of the diarthrodial joints in the body. Temporomandibular joints (TMJ) affected with RA may have pain, joint stiffness, difficulties in opening the mouth and open bite (as a secondary event to the severe condyle resorption) (7). The etiology of RA has been considered to be multifactorial, involving genetic factors, abnormal immunoreaction, the endocrine system (sex hormones) and environmental factors (infectious agents such as bacteria and viruses).

The present paper reports a case of bilateral asymptomatic fibrous-ankylosis of the TMJ associated with RA emphasizing the diagnosis of TMJ ankylosis.

\section{CASE REPORT}

A 49-year-old woman was referred to the Orofacial Pain Clinic of Bauru Dental School, USP, Brazil, with chief complaint of restricted mouth opening without pain, lasting approximately 4 months. On her first visit, the maximum interincisal mouth opening distance was $22 \mathrm{~mm}$ (Fig. 1).

The patient reported that she had been diagnosed 3 years before with RA by a rheumatologist and treatment with an immunosuppressive drug was indicated. The patient also reported that before the opening mouth limitation, she experienced a sensation of sand inside the ear when moving the jaw. The patient did not complain about any present or past TMJ pain. No parafunctional habits or macrotrauma were reported.

Physical examination showed limited maximum interincisal mouth opening (22 $\mathrm{mm})$, a symmetric opening without pain or joint sounds, accompanied by reduced mandibular eccentric movements. Assisted (passive) mouth opening did not increase the interincisal distance. Possible conditions causing limited mouth opening, such as anteriorly displaced discs and masticatory muscle myospasm, were ruled out.

Three different types of imaging diagnosis were performed: panoramic radiograph, cone beam computed tomography $(\mathrm{CBCT})$ and magnetic resonance image
(MRI). No significant findings were detected in the panoramic viewing. The CBCT, however, showed a coronal image with severe cortical irregularities in the mandibular condyle and temporal fossa, with no condylar translation at full mouth opening (Fig. 2). The T1-weighted MRI image of the TMJs showed poor delineation, with irregularities in the cortical bone of the fossa and condyle. Condylar translation was absent in open-mouth images (Fig. 3).

After the clinical (anamnesis and physical examination) and imaging evaluations, the diagnosis was fibrous-ankylosis in both TMJ secondary to RA.

\section{DISCUSSION}

Restricted mouth opening may be due to intraarticular or extra-articular factors. This great amount of possible causes for mouth opening limitation makes the diagnosis a difficult task. The dental practitioner should consider the participation of systemic conditions causing secondary manifestations in TMJ, as reported here. The differential diagnostic process for mouth opening limitation involves an extensive anamnesis, clinical and complementary exams, such as TMJ imaging. In the reported case, the diagnostic process was extremely challenging and, in addition to a detailed anamnesis and physical examination, complementary exams of the TMJ, such as CBCT and MRI, were the tipping point of the process.

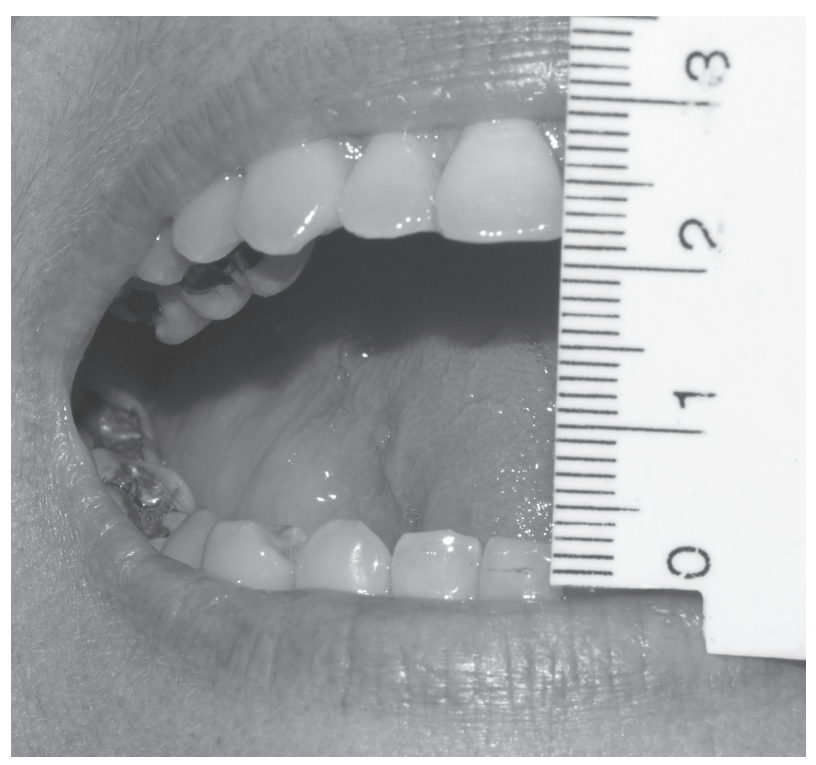

Figure 1. Maximum interincisal mouth opening distance $(22 \mathrm{~mm})$ on the first visit to the clinic. 
Limited movement of the mandible may reflect a disorder of the temporomandibular joint and/or masticatory muscles (3). In the reported case, the only complaint of the patient was a restricted mandibular opening without pain. The anamnesis and physical examination did not provide any information that could lead the diagnosis to a disc displacement without reduction, which has as diagnostic criteria the mouth opening limitation as a sudden event, with pain at opening and a history of clicking sounds (3). The patient did not complain of pain or any previous clicking sounds and the limitation was not a sudden event.

Masticatory muscle myospasm is a muscular disorder that is also characterized by mouth opening limitation, accompanied by pain (3). In such situation, when a vapocoolant spray is applied on the region of the masseter and temporalis muscles, the cold inhibits the pain and it is possible to get a normal assisted opening. In the reported case, this diagnostic test was performed and the limitation of opening persisted. After all, the only information reported by the patient in the anamnesis that could explain a possible cause for the
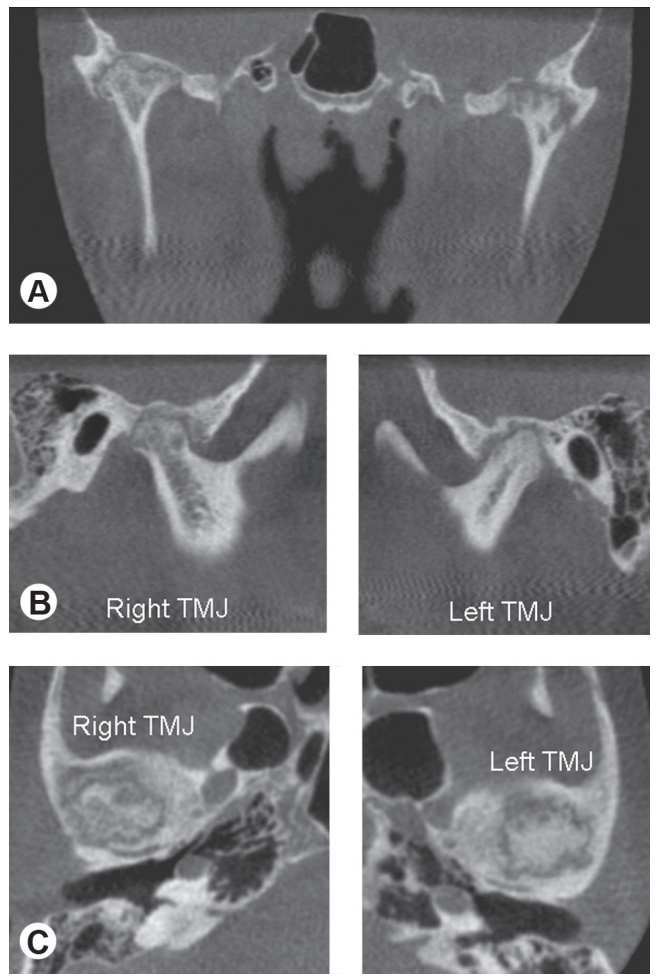

Figure 2. Cone beam computed tomography images showing a coronal image with severe cortical irregularities in the mandibular condyle and temporal fossa, with no condylar translation at full mouth opening (A: coronal. B: sagittal. C: axial). mouth opening limitation was the RA, diagnosed 3 years before by a rheumatologist. As RA may lead to a TMJ ankylosis characterized by mouth opening limitation (8), only a TMJ imaging (MRI and CBCT) could close the diagnosis and the images revealed a fibrous-ankylosis in both TMJs.

TMJ involvement in RA follows the same destructive path as do other joints. Generally, the severity of joint dysfunction is correlated with the stage of RA (2). In the early stage, it can seen a synovial hyperemia, lymphocyte infiltration, fibrinoid degeneration and pannus formation. The articular cartilage may be destroyed, and reactive and regenerative granulation tissue can be seen in the articular cavity. There may be fibrosis and cicatrization, and fibrous adhesion may be present (8). Fibrous-ankylosis is the last stage that a TMJ affected by RA can reach. TMJ ankylosis secondary to $\mathrm{RA}$ is a rare finding and has not been well documented (8). In this case, the patient's physician took too long to diagnose the RA and treated it with corticosteroids as a fibromyalgia, before a correct diagnosis was established.

As shown above, radiographic assessment is essential and critical in evaluating and treating patients with TMJ ankylosis. The use of computed tomography (CT) scans (including axial, coronal, and sagittal views with three-dimensional reconstruction) is helpful to fully
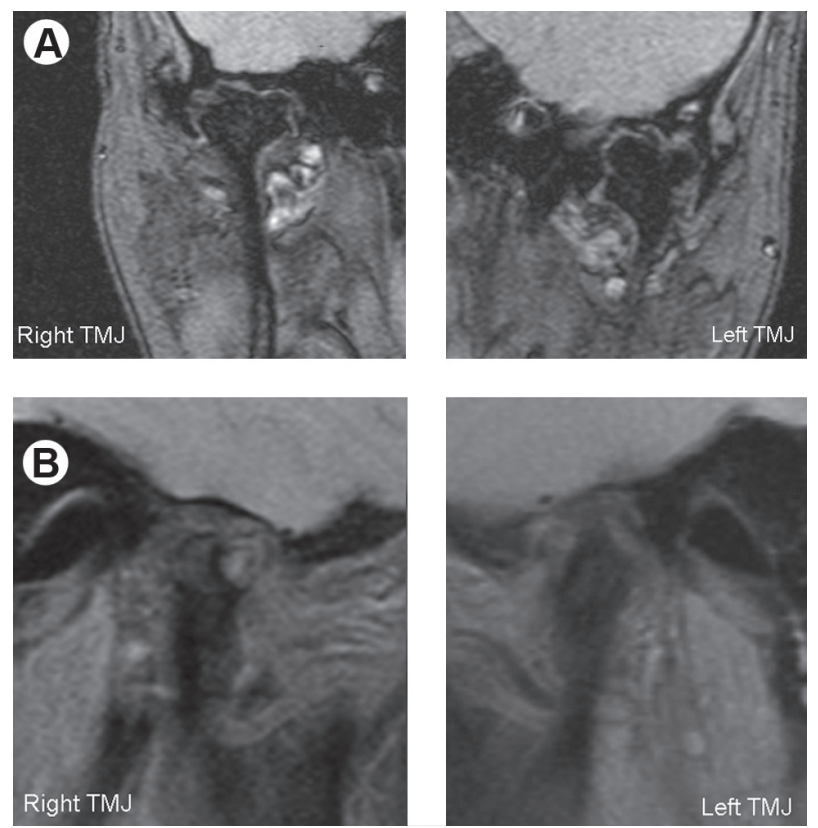

Figure 3. Magnetic resonance images of the TMJs showing poor delineation, with irregularities in the cortical bone of the fossa and condyle (A: coronal. B: sagittal). 
defining the extent of ankylosis as well as the relationship of the ankylotic mass to important anatomic structures, especially at the skull base (2). According to Long et al. (10), a tomographic image is the best imaging diagnosis tool to assess the type and extension of the ankylosis and to analyze the existence of a joint space (9). Diagnosis of fibrous-ankylosis is possible with the use of MRI, but the CT scan is superior in demonstrating bony pathology.

The interesting feature of this case is how a systemic disease (RA) can affect the TMJ when diagnosed late. Fibrous-ankylosis requires an invasive treatment. The surgical treatment is the only treatment proposed in cases of TMJ fibrous or bone ankylosis (11). Multiple operative procedures are used to manage TMJ ankylosis, but none has been universally accepted. The patient of this case was referred to a surgeon, but she chose first to try a physical therapy (ultrasound and manual therapy) what, as reported by the patient herself, brought her an improvement in the quality of life.

This case illustrates the importance of a well done clinical examination with complementary exams to a correct diagnosis of TMJ fibrous-ankylosis and the importance of a differential diagnosis in restricted mouth opening cases.

\section{RESUMO}

A Academia Americana de Dor Orofacial (AAOP) define anquilose da Articulação Temporomandibular (ATM) como restrição dos movimentos devido à adesão fibrosa intracapsular, alterações fibrosas nos ligamentos capsulares (fibroanquilose) e formação de massa óssea resultando na fusão dos componentes articulares (anquilose óssea). As características clínicas da Fibroanquilose são: capacidade severamente limitada de abertura bucal geralmente sem dor e sem ruídos articulares, com marcada deflexão para o lado afetado e marcada limitação de movimentos para o lado contralateral. Uma variedade de fatores pode causar anquilose da ATM, como trauma, condições inflamatórias locais e/ou sistêmicas, neoplasias e infecção na ATM. A artrite reumatóide (AR) é uma dessas condições sistêmicas inflamatórias que pode afetar a ATM e causar anquilose. O objetivo desse estudo é apresentar um caso de uma paciente, diagnosticada com Fibroanquilose da ATM bilateral e assintomática associada à AR. Esse caso ilustra a importância de um exame clínico bem realizado com exames complementares pode levar a um diagnóstico correto de Fibroanquilose da ATM e da importância do diagnóstico diferencial em casos de abertura bucal restrita.

\section{REFERENCES}

1. Gundlach KK. Ankylosis of the temporomandibular joint. J Craniomaxillofac Surg 2010;38:122-130.

2. Meredith A, Troulis MJ, Kaban LB. Hypomobility and hypermobility disorders of the temporomandibular joint. In:
Miloro M, editor. Peterson's principles of oral and maxillofacial surgery. Second ed. Hamilton: BC Decker Inc; 2004.

3. de Leeuw R. Orofacial pain: guidelines for assessment, diagnosis and management. 4th ed. Chicago: Quintessence; 2008.

4. Roychoudhury A, Parkash H, Trikha A. Functional restoration by gap arthroplasty in temporomandibular joint ankylosis: a report of 50 cases. Oral Surg Oral Med Oral Pathol Oral Radiol Endod 1999;87:166-169.

5. He D, Ellis E 3rd, Zhang Y. Etiology of temporomandibular joint ankylosis secondary to condylar fractures: the role of concomitant mandibular fractures. J Oral Maxillofac Surg 2008;66:77-84.

6. Chandra P, Dave PK. Temporomandibular joint ankylosis. Prog Clin Biol Res 1985;187:449-458.

7. Lin YC, Hsu ML, Yang JS, Liang TH, Chou SL, Lin HY. Temporomandibular joint disorders in patients with rheumatoid arthritis. J Chin Med Assoc 2007;70:527-534.

8. Kobayashi R, Utsunomiya T, Yamamoto H, Nagura H. Ankylosis of the temporomandibular joint caused by rheumatoid arthritis: a pathological study and review. J Oral Sci 2001;43:97-101.

9. Long X, Li X, Cheng Y, Yang X, Qin L, Qiao Y, et al.. Preservation of disc for treatment of traumatic temporomandibular joint ankylosis. J Oral Maxillofac Surg 2005;63:897-902.

10. El-Hakim IE, Metwalli SA. Imaging of temporomandibular joint ankylosis. A new radiographic classification. Dentomaxillofac Radiol 2002;31:19-23.

11. Güven O. A clinical study on temporomandibular joint ankylosis. Auris Nasus Larynx 2000;27:27-33.

Received September 16, 2012 Accepted December 5, 2012 